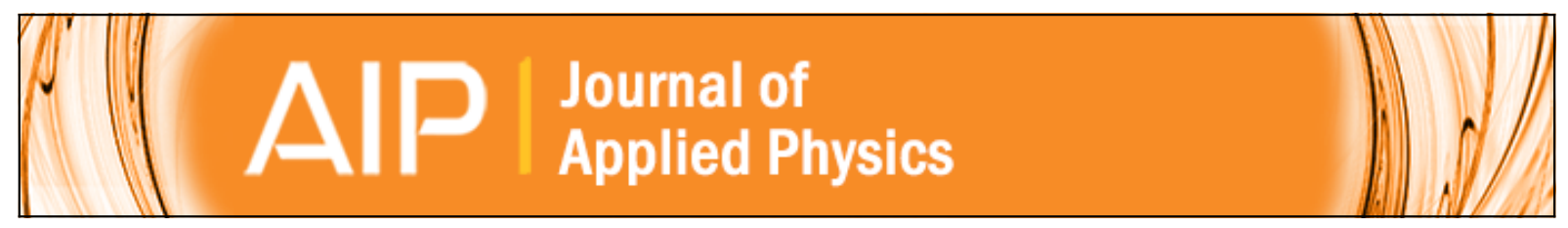

\title{
Carrier generation and transport in bulk heterojunction films processed with 1,8- octanedithiol as a processing additive
}

In-Wook Hwang, Shinuk Cho, Jin Young Kim, Kwanghee Lee, Nelson E. Coates, Daniel Moses, and Alan J. Heeger

Citation: Journal of Applied Physics 104, 033706 (2008); doi: 10.1063/1.2951957

View online: http://dx.doi.org/10.1063/1.2951957

View Table of Contents: http://scitation.aip.org/content/aip/journal/jap/104/3?ver=pdfcov

Published by the AIP Publishing

\section{Articles you may be interested in}

A low band gap, solution processable oligothiophene with a dialkylated diketopyrrolopyrrole chromophore for use in bulk heterojunction solar cells

Appl. Phys. Lett. 94, 103301 (2009); 10.1063/1.3086897

1,8-octanedithiol as a processing additive for bulk heterojunction materials: Enhanced photoconductive response Appl. Phys. Lett. 93, 072105 (2008); 10.1063/1.2969405

Efficacy of Ti O x optical spacer in bulk-heterojunction solar cells processed with 1,8-octanedithiol Appl. Phys. Lett. 92, 243308 (2008); 10.1063/1.2937844

Ultimate efficiency of polymer/fullerene bulk heterojunction solar cells Appl. Phys. Lett. 88, 093511 (2006); 10.1063/1.2181635

Generation of wavelength-dependent, periodic line pattern in metal nanoparticle-containing polymer films by femtosecond laser irradiation

Appl. Phys. Lett. 86, 153111 (2005); 10.1063/1.1897052

\section{A|P|Applied Physics} AlP | Letters

is pleased to announce Reuben Collins as its new Editor-in-Chief

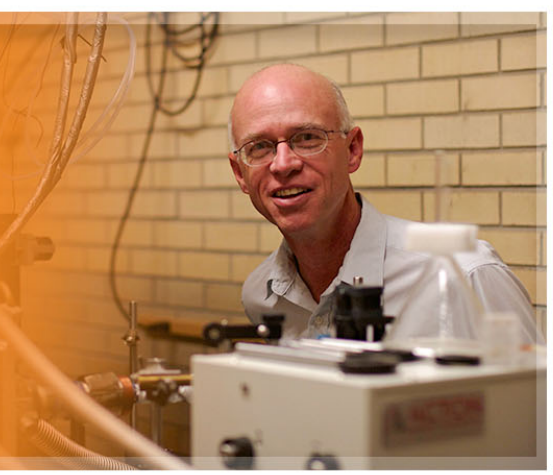




\title{
Carrier generation and transport in bulk heterojunction films processed with 1,8-octanedithiol as a processing additive
}

\author{
In-Wook Hwang, Shinuk Cho, Jin Young Kim, Kwanghee Lee, Nelson E. Coates, \\ Daniel Moses, ${ }^{\text {a) }}$ and Alan J. Heeger \\ Center for Polymers and Organic Solids, University of California, Santa Barbara, California 93106-5090, \\ USA
}

(Received 12 March 2008; accepted 28 April 2008; published online 4 August 2008)

\begin{abstract}
Improved performance of polymer-based solar cells based on poly[2,6-(4,4-bis-(2-ethylhexyl)-4Hcyclopenta[2,1-b;3,4- $b^{\prime}$ ]dithiophene)-alt-4,7-(2,1,3-benzo-thiadiazole)] PCPDTBT has been obtained by using 1,8-octanedithiol (ODT) as a processing additive in the polymer solution used to spin cast the bulk heterojunction films. Although ultrafast spectroscopy studies indicate that the carrier losses are reduced in the films processed with ODT [similar to the reduced carrier losses after thermal annealing of bulk heterojunction (BHJ) materials made from P3HT:PCBM], the magnitude of the reduction is not sufficient to explain the observed factor of 2 increase in the power conversion efficiency. From the analysis of carrier transport in field effect transistors, we find increased electron mobility in the PCPDTBT: $\mathrm{PC}_{70} \mathrm{BM}$ composites when fabricated with ODT, which is indicative of enhanced connectivity of $\mathrm{PC}_{70} \mathrm{BM}$ networks. The improved electron mobility appears to be the primary origin of the improved power conversion efficiency in BHJ films. (C) 2008 American Institute of Physics. [DOI: 10.1063/1.2951957]
\end{abstract}

\section{INTRODUCTION}

Polymer-based solar cells fabricated from bulk heterojunction (BHJ) materials comprising bicontinuous networks of regioregular poly(3-hexylthiophene) (rrP3HT) and the $[6,6]$-phenyl- $\mathrm{C}_{61}$ butyric acid methyl ester fullerene derivative $\mathrm{PC}_{60} \mathrm{BM}$ have demonstrated power conversion efficiencies of $5 \% .^{1-4}$ The efficiency in this system is limited, however, by poor overlap between the P3HT absorption spectrum and the solar radiation spectrum. The quest for higher solar cell efficiencies has therefore focused on smaller band gap polymers designed and synthesized to improve the harvesting of the solar radiation. ${ }^{5-12}$

The synthesis of copolymers comprising alternating electron-rich and electron-deficient units has been proven to be a successful route to small band gap semiconducting polymers. Following this synthetic strategy, the small band gap $\left(E_{g} \approx 1.46 \mathrm{eV}\right)$ copolymer, poly[2,6-(4,4-bis-(2-ethylhexyl)$4 H$-cyclopenta $\left[2,1-\mathrm{b} ; 3,4-b^{\prime}\right]$ dithiophene)-alt-4,7-(2,1,3-benzothiadiazole)] PCPDTBT, was synthesized. ${ }^{13}$ Even with the smaller energy gap, however, early studies of BHJ solar cells made of this copolymer with $\mathrm{PC}_{60} \mathrm{BM}$ as acceptor gave relatively low power conversion efficiency, $\eta_{e}=2.8 \%{ }^{14}$ By using 1,8-octanedithiol (ODT) as a processing additive in the polymer solution used for spin casting the BHJ films, PCPDTBT: $\mathrm{PC}_{70} \mathrm{BM}$ solar cells with $\eta_{e}=5.5 \%$ have been demonstrated.

Our earlier ultrafast spectroscopic study of PCPDTBT: $\mathrm{PC}_{60} \mathrm{BM}$ composites identified substantial carrier recombination losses at $t<600$ ps following

a)Electronic mail:moses@physics.ucsb.edu. photoexcitation. ${ }^{15}$ This loss of mobile carriers at early times reduces the collection efficiency and thereby limits the photovoltaic device performance. ${ }^{16}$ In similar studies of rPPHT: $\mathrm{PC}_{60} \mathrm{BM}$, we found significantly reduced recombination losses and improved power conversion efficiency in films that were thermally annealed at elevated temperature $\left(<150{ }^{\circ} \mathrm{C}\right)$. The postfabrication annealing resulted in a more complete phase separation (demixing) and improved crystallinity within the BHJ film. ${ }^{17}$

The use of the ODT processing additive appears to improve the PCPDTBT: $\mathrm{PC}_{60} \mathrm{BM}$ solar cell performance in direct analogy with the effect of thermal annealing of rrP3HT: $\mathrm{PC}_{60} \mathrm{BM}$, i.e., through control of the nanomorphology of PCPDTBT: $\mathrm{PC}_{70} \mathrm{BM}$ composite. ${ }^{18}$ This process generates changes in the film morphology that are correlated with the enhancement in the power conversion efficiency from $\eta_{e}=2.8 \%$ to $5.5 \% .^{18}$

Here we study the early time carrier generation and recombination of PCPDTBT: $\mathrm{PC}_{70} \mathrm{BM}$ composites fabricated using ODT by monitoring the time decay of the photoinduced charge transferred (CT) state. We have, in addition, studied the carrier mobility as measured in field effect transistors (FETs) fabricated with PCPDTBT: $\mathrm{PC}_{70} \mathrm{BM}$ composites using ODT as a processing additive. From the analysis of the data obtained from composite films fabricated with different ratios of the components and processed with and without ODT, we conclude the following: When the composites are fabricated using ODT and with increased content of $\mathrm{PC}_{70} \mathrm{BM}$, the carrier recombination loss at early times is reduced and the carrier (electron) mobility is increased. The combination of these two effects is responsible for the improved solar cell performance. 


\section{EXPERIMENTAL SECTION}

\section{A. Sample preparation}

The synthesis of the small band gap polymer PCPDTBT was published earlier. ${ }^{13}$ The $\mathrm{PC}_{70} \mathrm{BM}$ material was provided for our use by Konarka Technologies. The molecular weight of PCPDTBT was approximately $30000 \mathrm{~g} \mathrm{~mol}^{-1}$. All films used in the study were prepared in a nitrogen glovebox with an oxygen concentration of $\sim 1.5 \mathrm{ppm}$. The 1:2 and 1:3.6 PCPDTBT: $\mathrm{PC}_{70} \mathrm{BM}$ composite films were prepared by spin casting a chlorobenzene solution containing PCPDTBT (0.7 wt \%), $\mathrm{PC}_{70} \mathrm{BM}(1.4$ or 2.5 wt \%), and 1,8 -ODT (0 or 2.5 wt \%) into quartz substrates. Following the spin casting, the films were annealed at $80^{\circ} \mathrm{C}$ for $5 \mathrm{~min}$. During the TA measurements, the samples were kept under dynamic vacuum $\left(<10^{-4}\right.$ mbar $)$

\section{B. Time-resolved spectroscopy}

The femtosecond TA measurements were carried out with a dual-beam femtosecond spectrometer utilizing the second harmonic of an optical parametric amplifier as the pump and a white light continuum as the probe. ${ }^{19}$ The TA spectra were recorded by a scanning monochromator in the 380-1400 nm spectral region. Group velocity dispersion in the probe was compensated by shifting the delay to keep the pump-probe delay independent of wavelength. A germanium detector was used for detecting the TA signals in the near infrared regime. At each probe energy, the TA decay time constants were obtained by deconvoluting the measured signal from the pump Gaussian time profile, which is characterized by a full width at half maximum of $120 \mathrm{fs}$. The resulting decay profile was then fitted to a sum of exponential terms.

\section{Steady-state spectroscopy}

The steady-state absorption spectra were recorded by using a Beckman DU 800 spectrometer. The steady-state photo-induced absorption (PIA) spectra in midinfrared region were obtained at low temperature $(90 \mathrm{~K})$ by transmittance measurements in an automatic FT-IR spectrometer from thick films deposited on $\mathrm{KBr}$ substrates. The excitation source was a continuous wave $\mathrm{Ar}^{+}$or $\mathrm{He}-\mathrm{Ne}$ laser tuned at 514 and $632.8 \mathrm{~nm}$.

\section{Photovoltaic cells}

A detailed description of the solar cell device fabrication was published earlier. ${ }^{18} \mathrm{Al}$ and ITO were used as collecting electrodes, while poly(3,4-ethylenedioxylenethiophene)polystylene sulfonic acid (PEDOT:PSS, Baytron PH) was used as hole transporting layer. Current density versus voltage curves was obtained using a Keithley 236 source measurement unit.

\section{E. FET devices}

FET devices were fabricated following earlier publications. ${ }^{20}$ The source and drain electrodes (Al) with 50 $\mathrm{nm}$ thickness were used. Active layers were prepared by spin casting (at $3000 \mathrm{rpm}$ ) the chlorobenzene solution containing
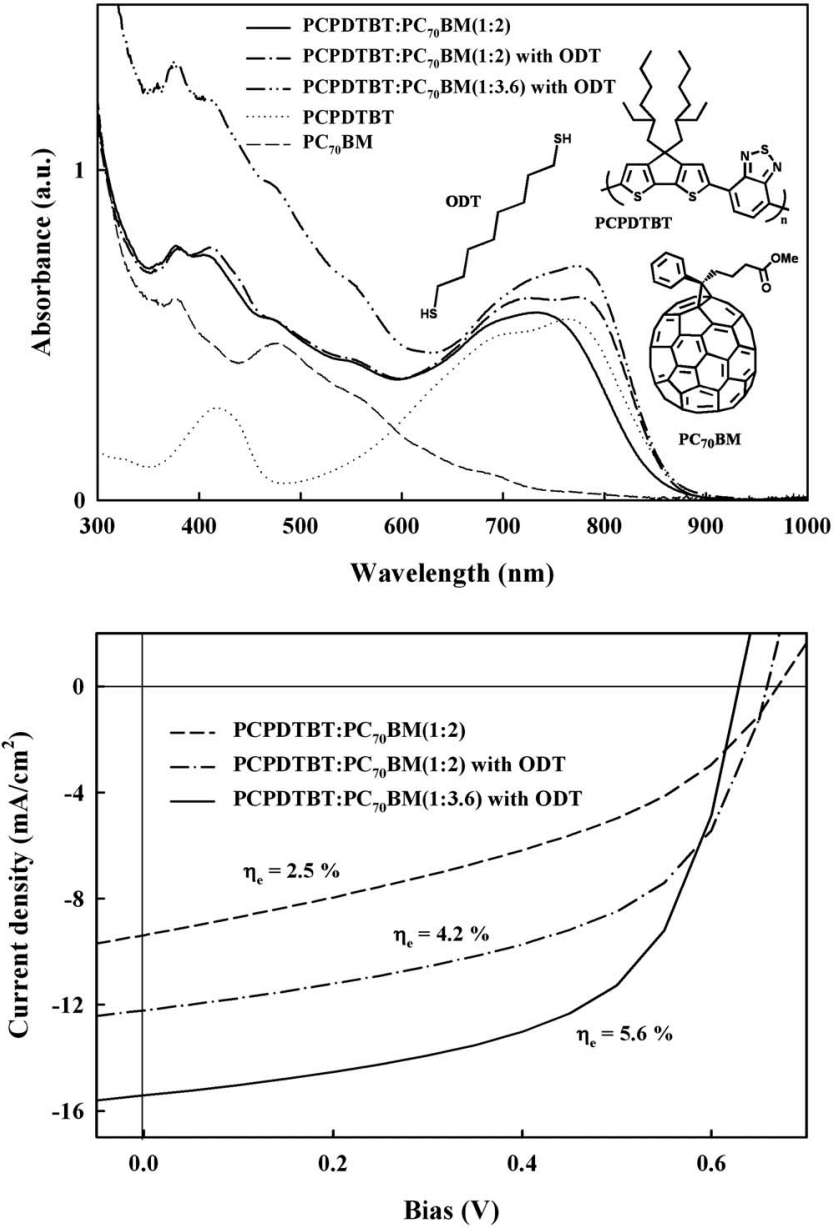

FIG. 1. (a) Steady-state absorption spectra obtained from films of PCPDTBT, $\mathrm{PC}_{70} \mathrm{BM}$, and PCPDTBT: $\mathrm{PC}_{70} \mathrm{BM}$ BHJ materials (1:2 composite fabricated with and without ODT and 1:3.6 composite fabricated with ODT). The inset shows the molecular structures of the materials. (b) The current-voltage characteristics of solar cells using PCPDTBT: $\mathrm{PC}_{70} \mathrm{BM}$ BHJ materials under AM $1.5 \mathrm{G}$ illumination from a calibrated solar simulator with irradiation intensity of $100 \mathrm{~mW} / \mathrm{cm}^{2}$. The device performances are summarized as follows: the pure 1:2 PCPDTBT: $\mathrm{PC}_{70} \mathrm{BM}$ cell shows $J_{s c}$ $=9.38 \mathrm{~mA} / \mathrm{cm}^{2}, \quad V_{o c}=0.67 \mathrm{~V}, \quad F F=0.40$, and $\eta_{e}=2.53 \%$; the $1: 2$ PCPDTBT: $\mathrm{PC}_{70} \mathrm{BM}$ cell fabricated with ODT shows $J_{s c}=12.12 \mathrm{~mA} / \mathrm{cm}^{2}$, $V_{o c}=0.66 \mathrm{~V}, F F=0.53$, and $\eta_{e}=4.24 \%$; and the 1:3.6 PCPDTBT: $\mathrm{PC}_{70} \mathrm{BM}$ cell fabricated with ODT shows $J_{s c}=15.42 \mathrm{~mA} / \mathrm{cm}^{2}, V_{o c}=0.63 \mathrm{~V}, F F$ $=0.58$, and $\eta_{e}=5.63 \%$.

the composites $(0.5$ wt \%) into substrates. Electrical characterization was performed using a Keithley semiconductor parametric analyzer (Keithley 4200). Before FET measurements, the devices were kept under a high vacuum $\left(<10^{-6}\right.$ Torr $)$ for $24 \mathrm{~h}$ to completely remove 1,8 -ODT from the composite films. Without the removal of 1,8-ODT, all the composites exhibited smaller electron mobilities $(\sim 1$ $\left.\times 10^{-4} \mathrm{~cm}^{2} / \mathrm{V} \mathrm{s}\right)$ than shown in Fig. 6 .

\section{RESULTS AND DISCUSSION}

\section{A. Absorption and solar cell efficiency}

Figure 1(a) shows the steady-state absorption spectra obtained from various material components and composites; the molecular structures of PCPDTBT and $\mathrm{PC}_{70} \mathrm{BM}$ are included as well. PCPDTBT exhibits a broad absorption profile 
polymer excitation $\left(\lambda_{\mathrm{ex}}=\mathbf{7 0 0} \mathrm{nm}\right)$

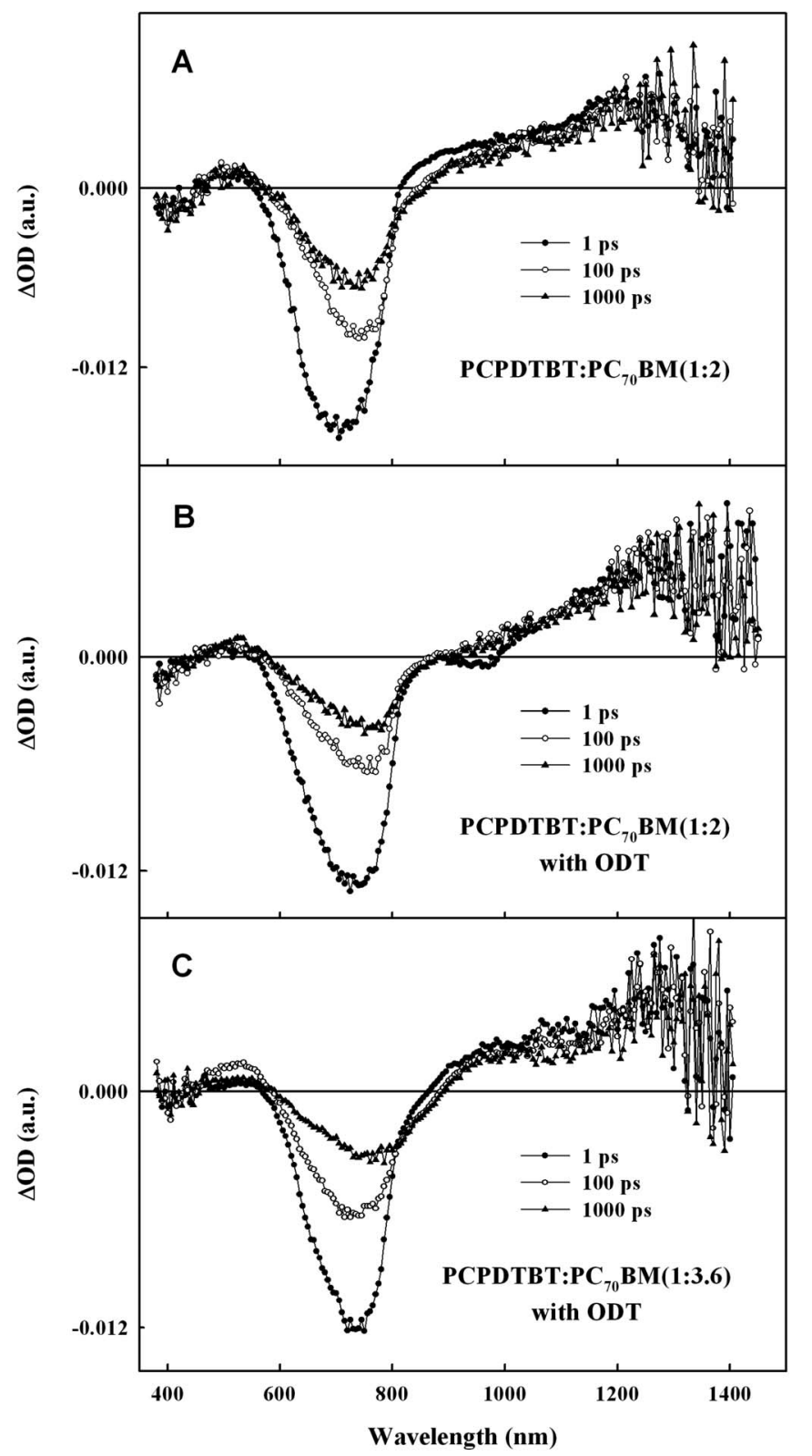

$\mathrm{PC}_{70} \mathrm{BM}$ excitation $\left(\lambda_{\mathrm{ex}}=500 \mathrm{~nm}\right)$

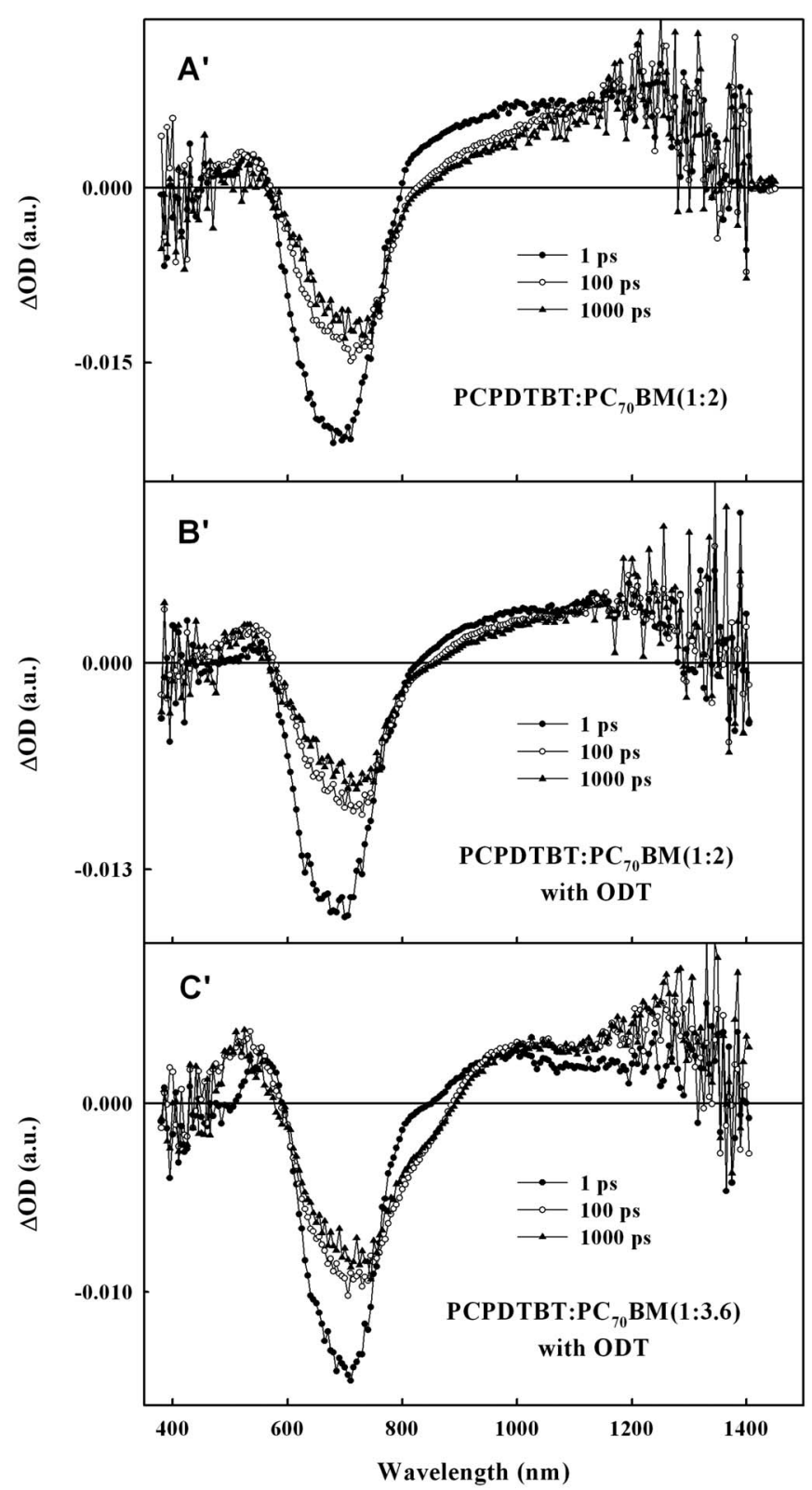

FIG. 2. TA spectra obtained from films of PCPDTBT: $\mathrm{PC}_{70} \mathrm{BM}$ BHJ materials $\left[1: 2\right.$ composite fabricated without $\left(\mathrm{A}, A^{\prime}\right)$ and with $\left(\mathrm{B}, B^{\prime}\right)$ ODT and 1:3.6 composite fabricated with ODT $\left(\mathrm{C}, C^{\prime}\right)$ ] following the photoexcitation of PCPDTBT and $\mathrm{PC}_{70} \mathrm{BM} .700 \mathrm{~nm}$ pump was used in photoexcitation of PCPDTBT (left panels) and $500 \mathrm{~nm}$ pump was used to excite the $\mathrm{PC}_{70} \mathrm{BM}$ (right panels). The pump intensity was $50 \mu \mathrm{J} / \mathrm{cm}^{2}$. The PIA bands due to $\mathrm{CT}$ state and interband polaron transition $\left(P_{2}\right)$ are indicated.

ranging from the ultraviolet (UV) to $900 \mathrm{~nm}\left(E_{g}\right.$ $\sim 1.46 \mathrm{eV}$ ). The $\mathrm{PC}_{70} \mathrm{BM}$ shows strong absorption in the $\mathrm{UV}$ and a gradual decrease to $700 \mathrm{~nm}$. Note, however, that the $\mathrm{PC}_{70} \mathrm{BM}$ shows a local maximum at $480 \mathrm{~nm}$ and relatively strong absorption across the visible portion of the spectrum. The data from the PCPDTBT: $\mathrm{PC}_{70} \mathrm{BM}$ composites are a superposition of the contributions of the two components. The absorption "dip" of PCPDTBT at $\sim 500 \mathrm{~nm}$ is well compensated in magnitude by the absorption peak of $\mathrm{PC}_{70} \mathrm{BM}$ at the same energy. The composite films made using the ODT additive show a redshift in the absorption spectra. ${ }^{18}$ The redshift is indicative of increased planarization and extension of the conjugated segments in the polymer composites. $^{23,24}$

The current-voltage characteristics and corresponding solar cell efficiencies $\left(\eta_{e}\right)$ obtained under $100 \mathrm{~mW} / \mathrm{cm}^{2}$ from devices made with PCPDTBT: $\mathrm{PC}_{70} \mathrm{BM}$ are presented in Fig. 1(b). The data show efficiency improvements from $\eta_{e}=2.5 \%$ to $4.2 \%$ for solar cells processed with ODT and made with 1:2 composite (ratio of PCPDTPT to $\mathrm{PC}_{70} \mathrm{BM}$ by weight), and from $\eta_{e}=2.5 \%$ to $5.6 \%$ for devices processed with ODT and increased $\mathrm{PC}_{70} \mathrm{BM}$ content (1:3.6 by weight). Because the absorption spectra shown in Fig. 1(a) cannot account for these large changes in the power conversion ef- 
polymer excitation $\left(\lambda_{\mathrm{ex}}=700 \mathrm{~nm}\right)$

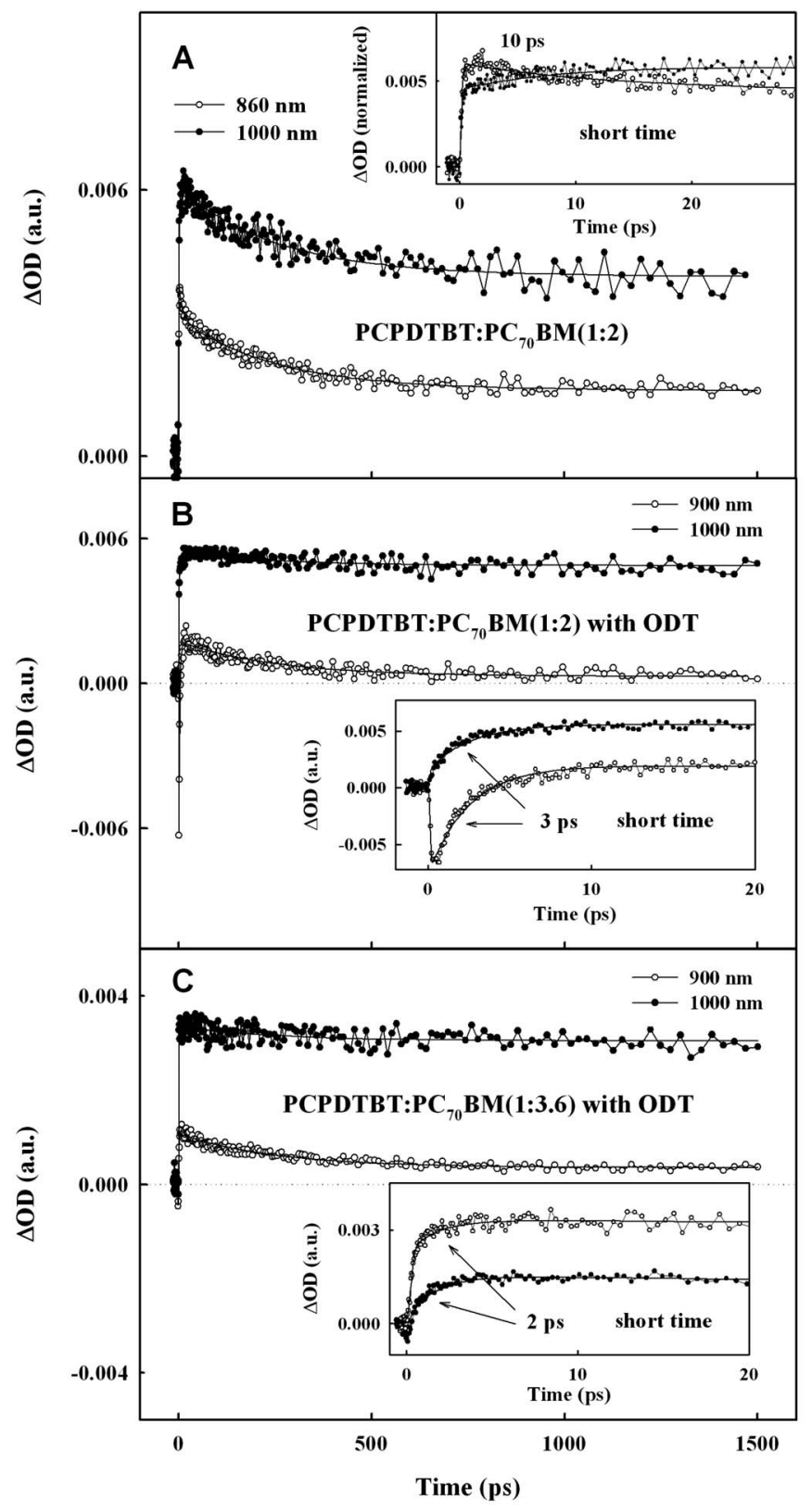

$\mathrm{PC}_{70} \mathrm{BM}$ excitation $\left(\lambda_{\mathrm{ex}}=500 \mathrm{~nm}\right)$

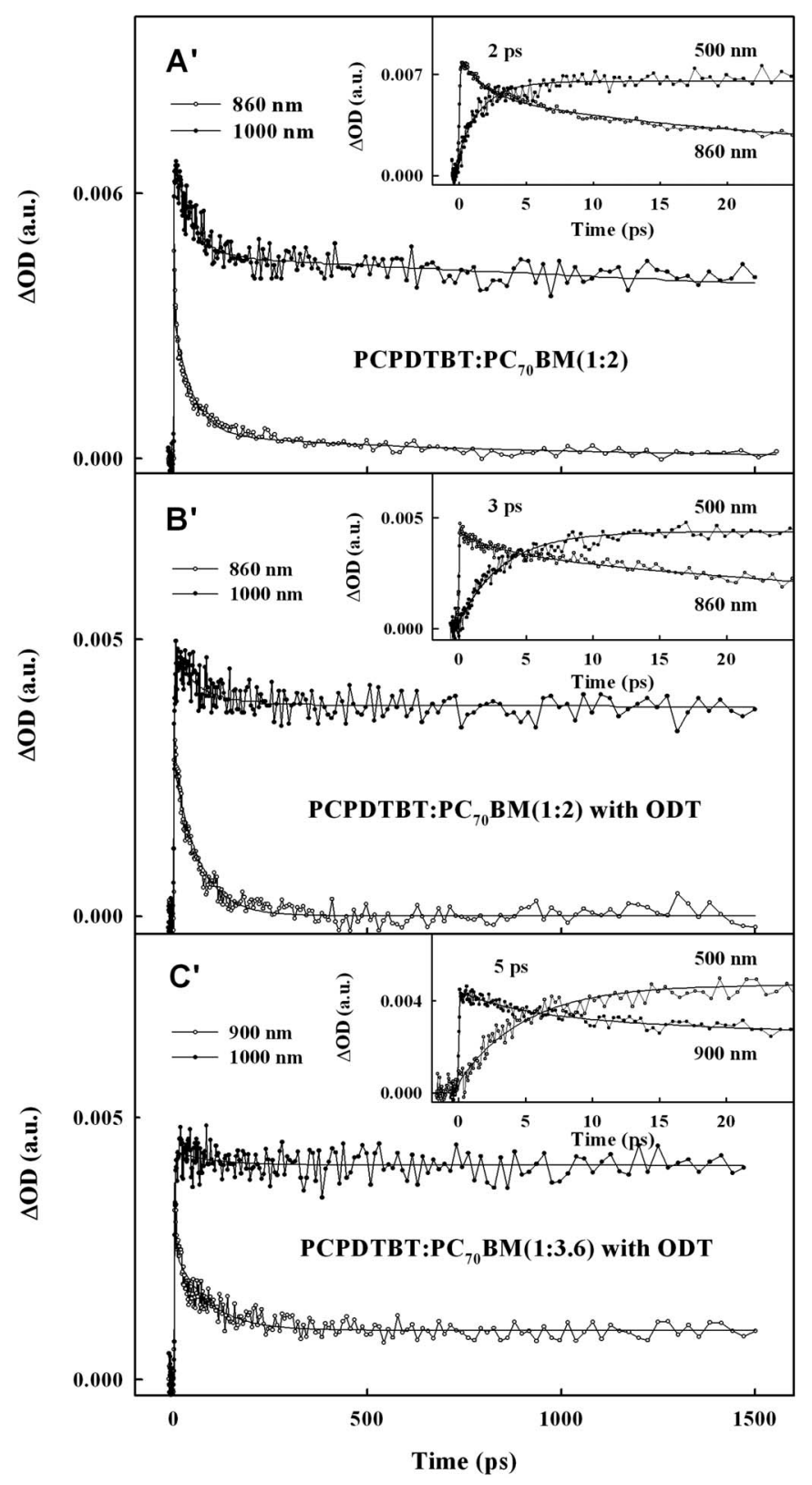

FIG. 3. PIA-decay profiles obtained from films of PCPDTBT: $\mathrm{PC}_{70} \mathrm{BM}$ BHJ materials $\left[1: 2\right.$ composite fabricated without (A, $\left.A^{\prime}\right)$ and with (B, $\left.B^{\prime}\right)$ ODT and 1:3.6 composite fabricated with ODT $\left.\left(\mathrm{C}, C^{\prime}\right)\right]$ following the photoexcitation of polymer (left panels) and that of $\mathrm{PC}_{70} \mathrm{BM}$ (right panels). The inset of each panel shows the fast time region of the PIA decay. The probe wavelengths are indicated in each panel. The pump wavelength was $700 \mathrm{~nm}$ for the polymer excitation and $500 \mathrm{~nm}$ for the $\mathrm{PC}_{70} \mathrm{BM}$ excitation. Pump intensity was $50 \mu \mathrm{J} / \mathrm{cm}^{2}$, which is sufficiently low to avoid bimolecular (annihilation) processes.

ficiency, detailed studies of the carrier generation and transport properties are needed to understand the significant improvements in the performance.

\section{B. Transient absorption spectra}

The transient absorption (TA) spectra obtained from PCPDTBT: $\mathrm{PC}_{70} \mathrm{BM}$ films are presented in Fig. 2. Although there is an overlap in the absorption spectra of PCPDTBT and $\mathrm{PC}_{70} \mathrm{BM}$, photoexcitation at $700 \mathrm{~nm}$ can be used to selectively excite the polymer in the composite (left panels of Fig. 2), while excitation at $500 \mathrm{~nm}$ can be used to selectively excite the $\mathrm{PC}_{70} \mathrm{BM}$ (right panels of Fig. 2). Note that in Fig.
$2\left(\mathrm{~A}, A^{\prime}\right)$, the PIA signal at $800-1000 \mathrm{~nm}$ decays within 100 ps after the photoexcitation, whereas the PIA at $\lambda$ $>1000 \mathrm{~nm}$ persists with an almost constant amplitude beyond $1000 \mathrm{ps}$. The long-lived PIA at $\lambda>1000 \mathrm{~nm}$ is attributed to mobile carriers (polarons).

Based on the conclusions in earlier PIA studies of PCPDTBT: $\mathrm{PC}_{60} \mathrm{BM}^{15}{ }^{15}$ we attribute the short-lived PIA at 800-1000 nm to the intermediate CT state generated via ultrafast electron transfer from PCPDTBT to $\mathrm{PC}_{70} \mathrm{BM}$ and hole transfer from $\mathrm{PC}_{70} \mathrm{BM}$ to $\mathrm{PCPDTBT}$. Mobile carriers are generated as the bound state dissociates, a process in competition with carrier recombination while in the CT state. 
TABLE I. TA-decay parameters obtained from films of PCPDTBT: $\mathrm{PC}_{70} \mathrm{BM}$ BHJ materials (1:2 composite fabricated without and with ODT and 1:3.6 composite fabricated with ODT) following the photoexcitation of PCPDTBT. The pump wavelength was $700 \mathrm{~nm}$ and the intensity was $50 \mathrm{~mJ} / \mathrm{cm}^{2}$.

\begin{tabular}{|c|c|c|c|}
\hline & \multicolumn{3}{|c|}{$\begin{array}{l}\text { Fitted decay times }{ }^{\mathrm{a}} \\
(\mathrm{ps})\end{array}$} \\
\hline $\begin{array}{c}\text { Probe wavelength } \\
\qquad(\mathrm{nm})\end{array}$ & $\tau_{1}$ & $\tau_{2}$ & $\tau_{3}$ \\
\hline \multicolumn{4}{|c|}{ PCPDTBT: PC $_{70} \mathrm{BM}(1: 2)$} \\
\hline 700 & $10(17 \%)$ & $250(44 \%)$ & Long (39\%) \\
\hline 860 & $10(20 \%)$ & $250(42 \%)$ & Long $(38 \%)$ \\
\hline 1000 & $10^{\text {rise }}$ & $250(32 \%)$ & Long $(68 \%)$ \\
\hline \multicolumn{4}{|c|}{ PCPDTBT: $\mathrm{PC}_{70} \mathrm{BM}(1: 2)$ with ODT } \\
\hline 700 & $3(35 \%)$ & $250(37 \%)$ & Long $(28 \%)$ \\
\hline 900 & $3^{\text {rise }}$ & $250(83 \%)$ & Long $(17 \%)$ \\
\hline 1000 & $3^{\text {rise }}$ & $250(10 \%)$ & Long $(90 \%)$ \\
\hline \multicolumn{4}{|c|}{ PCPDTBT: $\mathrm{PC}_{70} \mathrm{BM}$ (1:3.6) with ODT } \\
\hline 700 & $2(26 \%)$ & $250(40 \%)$ & Long $(34 \%)$ \\
\hline 900 & $2^{\text {rise }}$ & $250(67 \%)$ & Long (33\%) \\
\hline 1000 & $2^{\text {rise }}$ & $250(09 \%)$ & Long $(91 \%)$ \\
\hline
\end{tabular}

${ }^{\mathrm{a}}$ Using the fitting function $\Delta O D(t)=A_{1} \exp \left(-t / t_{1}\right)+A_{2} \exp \left(-t / t_{2}\right)+A_{3} \exp ($ $-t / t_{3}$ ), where $\triangle O D(t)$ is the TA intensity, $A$ is the amplitude (noted in parentheses as the normalized percentage, i.e., $\left.\left[A_{i} /\left(A_{1}+A_{2}+A_{3}\right)\right] 100\right)$, and $\tau$ is the fitted decay time.

We note the large photobleaching (PB) signal at $700 \mathrm{~nm}$ that originates from the PCPDTBT component in the PCPDTBT: $\mathrm{PC}_{70} \mathrm{BM}$ composite (see the left panels in Fig. 2). The same PB signal is observed at the right panels in Fig. 2 generated by pumping, primarily via $\mathrm{PC}_{70} \mathrm{BM}$ absorption. The $\mathrm{PB}$ response from the polymer at $700 \mathrm{~nm}$ is clearly observed but there is no bleaching signal from the $\mathrm{PC}_{70} \mathrm{BM}$ component at $\sim 500 \mathrm{~nm}$. These data are consistent with the expected ultrafast $(t<1 \mathrm{ps})$ hole transfer from the highest occupied molecular orbital (HOMO) of $\mathrm{PC}_{70} \mathrm{BM}$ (at $-6.1 \mathrm{eV}$ below the vacuum) to the higher energy HOMO of PCPDTBT (at $-5.0 \mathrm{eV}$ ). The final state following the electron transfer from PCPDTBT to $\mathrm{PC}_{70} \mathrm{BM}$ is identical to the final state following the hole transfer from $\mathrm{PC}_{70} \mathrm{BM}$ to PCPDTB. Thus, the PB spectra are expected and observed to be the same.

The TA spectra obtained from PCPDTBT: $\mathrm{PC}_{70} \mathrm{BM}$ composites processed with ODT, [Fig. $2\left(\mathrm{~B}, B^{\prime}\right)$ ] and [Fig. 2 (C, $\left.C^{\prime}\right)$ ], exhibit generally reduced PIA response at $800-1000$ $\mathrm{nm}$ (i.e., at CT state), compared to the same bands in Fig. 2 $\left(\mathrm{A}, A^{\prime}\right)$, indicating that in films processed with ODT, a larger fraction of the CT state dissociates into long-lived mobile carriers consistent with the higher efficiency. ${ }^{15}$

\section{Carrier generation}

Figure 3 shows the PIA-decay profiles probed in the CT $(860-900 \mathrm{~nm})$ and mobile polaron $(1000 \mathrm{~nm})$ regimes of the PCPDTBT: $\mathrm{PC}_{70} \mathrm{BM}$ composites. The results of the rise and decay times and the relative amplitudes obtained from fitting the data to three exponential terms are listed in Tables I and II.

Probing at $1000 \mathrm{~nm}$ following the pumping of PCPDTBT or $\mathrm{PC}_{70} \mathrm{BM}$ networks, we find that all the $\mathrm{BHJ}$ mate-
TABLE II. TA-decay parameters obtained from films of PCPDTBT: $\mathrm{PC}_{70} \mathrm{BM}$ BHJ materials (1:2 composite fabricated without and with ODT and 1:3.6 composite fabricated with ODT) following the photoexcitation of $\mathrm{PC}_{70} \mathrm{BM}$. The pump wavelength was $500 \mathrm{~nm}$ and the intensity was $50 \mathrm{~mJ} / \mathrm{cm}^{2}$.

\begin{tabular}{|c|c|c|c|}
\hline \multirow[b]{2}{*}{$\begin{array}{l}\text { Probe wavelength } \\
\qquad(\mathrm{nm})\end{array}$} & \multicolumn{3}{|c|}{$\begin{array}{c}\text { Fitted decay times }{ }^{\mathrm{a}} \\
(\mathrm{ps})\end{array}$} \\
\hline & $\tau_{1}$ & $\tau_{2}$ & $\tau_{3}$ \\
\hline \multicolumn{4}{|c|}{ PCPDTBT: PC $_{70} \mathrm{BM}(1: 2)$} \\
\hline 700 & $0.3^{\text {rise }}$ & $47(50 \%)$ & Long $(50 \%)$ \\
\hline 860 & $2(61 \%)$ & $47(32 \%)$ & Long $(07 \%)$ \\
\hline 1000 & $2^{\text {rise }}$ & $47(33 \%)$ & Long $(67 \%)$ \\
\hline \multicolumn{4}{|c|}{ PCPDTBT: $\mathrm{PC}_{70} \mathrm{BM}(1: 2)$ with ODT } \\
\hline 700 & $0.3^{\text {rise }}$ & $66(44 \%)$ & Long $(56 \%)$ \\
\hline 860 & $3(8 \%)$ & $66(92 \%)$ & \\
\hline 1000 & $3^{\text {rise }}$ & $66(19 \%)$ & Long $(81 \%)$ \\
\hline \multicolumn{4}{|c|}{ PCPDTBT: $\mathrm{PC}_{70} \mathrm{BM}$ (1:3.6) with ODT } \\
\hline 700 & $0.7^{\text {rise }}$ & $87(36 \%)$ & Long $(64 \%)$ \\
\hline 900 & $5(37 \%)$ & $87(39 \%)$ & Long $(24 \%)$ \\
\hline 1000 & $5^{\text {rise }}$ & $87(15 \%)$ & Long $(85 \%)$ \\
\hline
\end{tabular}

离Using the fitting function $\Delta O D(t)=A_{1} \exp \left(-t / t_{1}\right)+A_{2} \exp \left(-t / t_{2}\right)+A_{3} \exp ($ $-t / t_{3}$ ), where $\Delta O D(t)$ is the TA intensity, $A$ is the amplitude (noted in parentheses as the normalized percentage, i.e., $\left.\left[A_{\mathrm{i}} /\left(A_{1}+A_{2}+A_{3}\right)\right] 100\right)$, and $\tau$ is the fitted decay time.

rials exhibit photoinduced absorption that is constant in magnitude beyond $1.5 \mathrm{~ns}$, a characteristic of long-lived mobile carriers. ${ }^{15}$ The initial decay component is characterized by a time constant of $\sim 250 \mathrm{ps}$ for the polymer excitation (left panels in Fig. 3) and $47-87$ ps for the $\mathrm{PC}_{70} \mathrm{BM}$ excitation (right panels in Fig. 3). When probed at $860-900 \mathrm{~nm}$ (at the CT intermediate state), similar but more pronounced (i.e., with greater amplitude) decay rates are evident as well. We attribute the time constants of $\sim 250 \mathrm{ps}$ and $47-87 \mathrm{ps}\left(\tau_{2}\right.$ in Tables I and II) to the rate of recombination from the CT state following the photoexcitation when pumping the PCPDTBT and the $\mathrm{PC}_{70} \mathrm{BM}$, respectively.

The data presented in Fig. 3 indicate a reduced amplitude of the short-lived component of the PIA decay when probed at $1000 \mathrm{~nm}$ in films processed with ODT, as is evident in comparing the data in Fig. 3 (B, $\left.B^{\prime}\right)$ and Fig. 3 (C, $\left.C^{\prime}\right)$ with the data in Fig. $3\left(\mathrm{~A}, A^{\prime}\right)$. This observation indicates reduced carrier recombination losses in the BHJ composites processed with ODT. Quantitative values for the carrier recombination loss are obtained from the PB-decay measurements described in Sec. II D.

The PIA signals in the picosecond time regime and the characteristic signal decay and rise times are shown with higher temporal resolution in the inset of each panel in Fig. 3. The data displayed in the insets of Fig. 3 show a fast decay of the CT state (when probed at 860-900 nm) and the corresponding rise in the number of mobile carriers (when probed at $1000 \mathrm{~nm}$ ), which are consistent with the dissociation of the bound state and the generation of mobile carriers. ${ }^{15,17}$

Additionally, regardless of the excitation photon energy used $\left(500 \mathrm{~nm}\right.$ for exciting primarily the $\mathrm{PC}_{70} \mathrm{BM}$ or $700 \mathrm{~nm}$ for exciting the polymer component), the time resolved spec- 
polymer excitation $\left(\lambda_{\mathrm{ex}}=700 \mathrm{~nm}\right)$

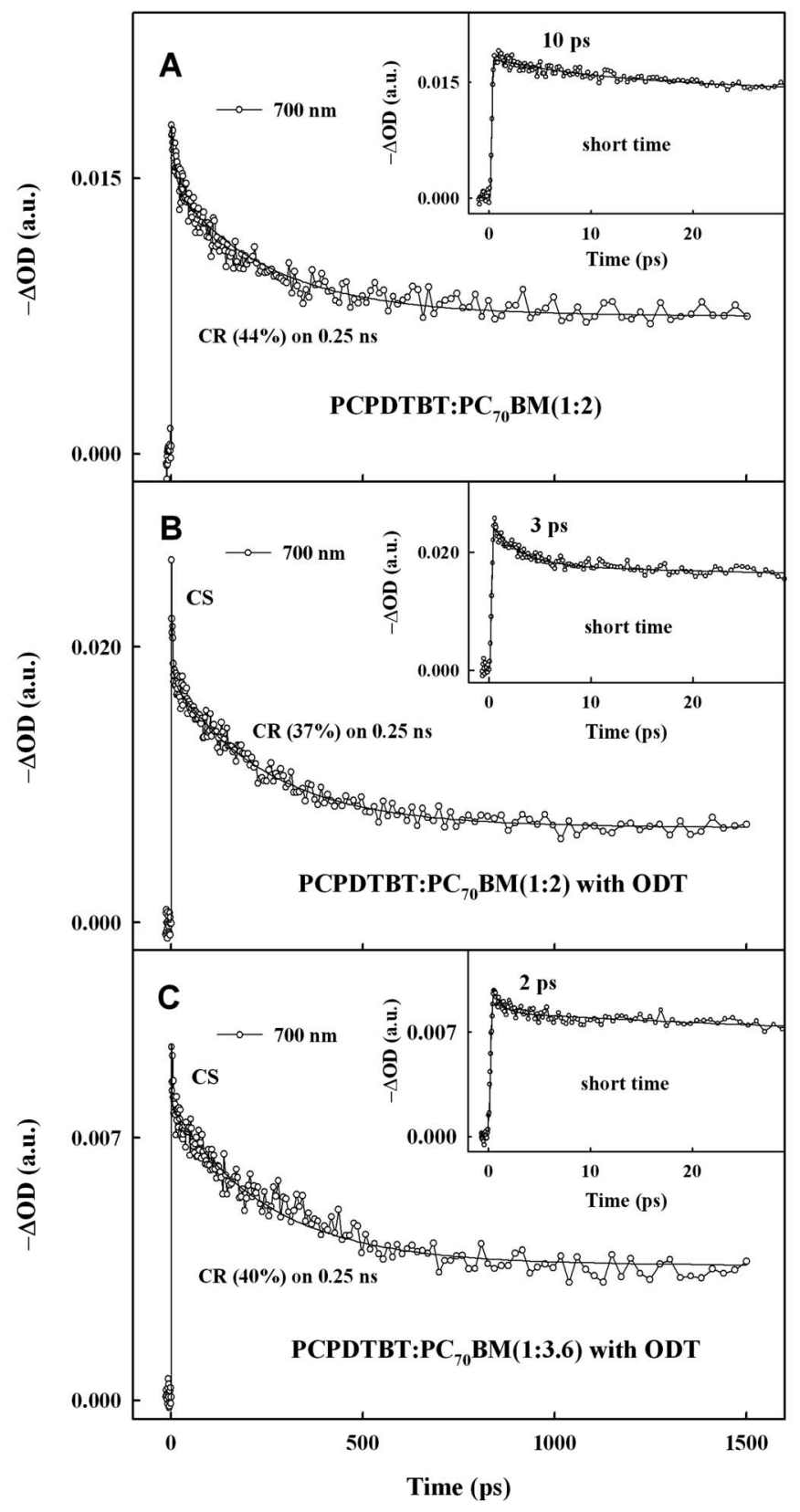

$\mathrm{PC}_{70} \mathrm{BM}$ excitation $\left(\lambda_{\mathrm{ex}}=500 \mathrm{~nm}\right)$

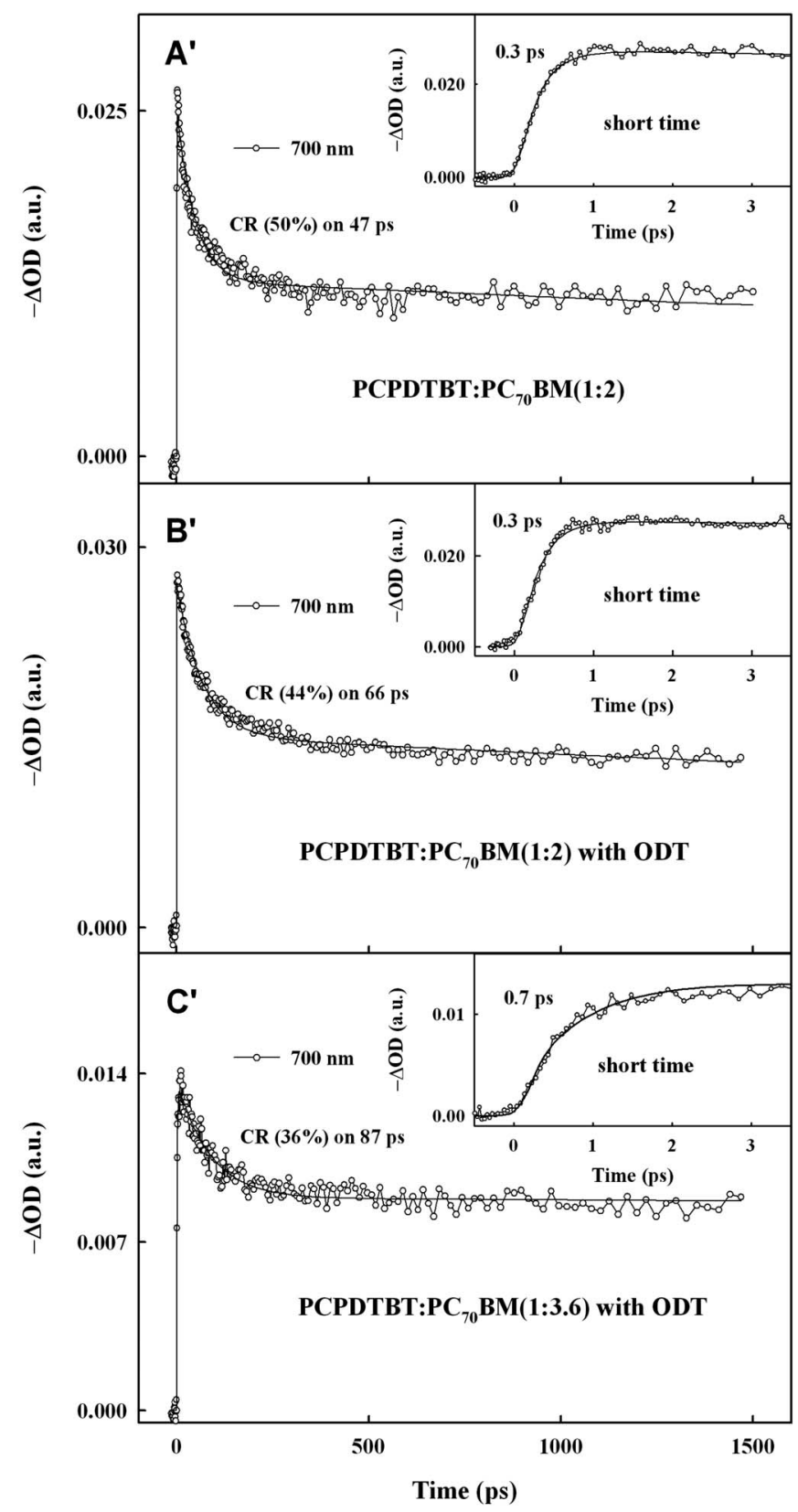

FIG. 4. (a) PB-recovery decay profiles obtained from films of PCPDTBT: $\mathrm{PC}_{70} \mathrm{BM} \mathrm{BHJ}$ materials $\left[1: 2\right.$ composite fabricated without (A, $\left.A^{\prime}\right)$ and with (B, $B^{\prime}$ ) ODT and 1:3.6 composite fabricated with ODT $\left(\mathrm{C}, \mathrm{C}^{\prime}\right)$ ] following the photoexcitation of polymer (left panels) and that of $\mathrm{PC}_{70} \mathrm{BM}$ (right panels). The inset of each panel indicates the fast time region of the $\mathrm{PB}$ decay. The pump wavelength was $700 \mathrm{~nm}$ for the polymer excitation and $500 \mathrm{~nm}$ for the $\mathrm{PC}{ }_{70} \mathrm{BM}$ excitation. Pump intensity was $50 \mu \mathrm{J} / \mathrm{cm}^{2}$, which is sufficiently low to avoid bimolecular (annihilation) processes. All the PB decays were probed at $700 \mathrm{~nm}$. In the inset, CS and CR denote charge separation and charge recombination, respectively.

troscopy indicates reduced carrier loss from early time recombination in BHJ films processed using the ODT additive. The reduced carrier loss is apparent from the significantly smaller magnitude of the prompt decay component in Fig. 3 $\left(\mathrm{B}, B^{\prime}\right)$ and Fig. $3\left(\mathrm{C}, C^{\prime}\right)$ as compared with that in Fig. 3 (A, $\left.A^{\prime}\right)$.

\section{Carrier recombination losses}

The PB decays obtained from the PCPDTBT: $\mathrm{PC}_{70} \mathrm{BM}$ composites are presented in Fig. 4. Generally, PB recovery reflects the recombination dynamics of all the photoexcitations. Thus from the analysis of these data, we estimate the carrier recombination loss while bound on the CT state.

The PB decays following the photoexcitation of PCPDTBT (left panels in Fig. 4) are fitted to a sum of three exponential terms - an initial decay with a time constant of 2-10 ps followed by two decay components characterized by a time constant of $\sim 250 \mathrm{ps}$ and an almost constant PB response in the nanosecond regime. When photoexcited at $\mathrm{PC}_{70} \mathrm{BM}$ absorption band (right panels in Fig. 4), the PB 


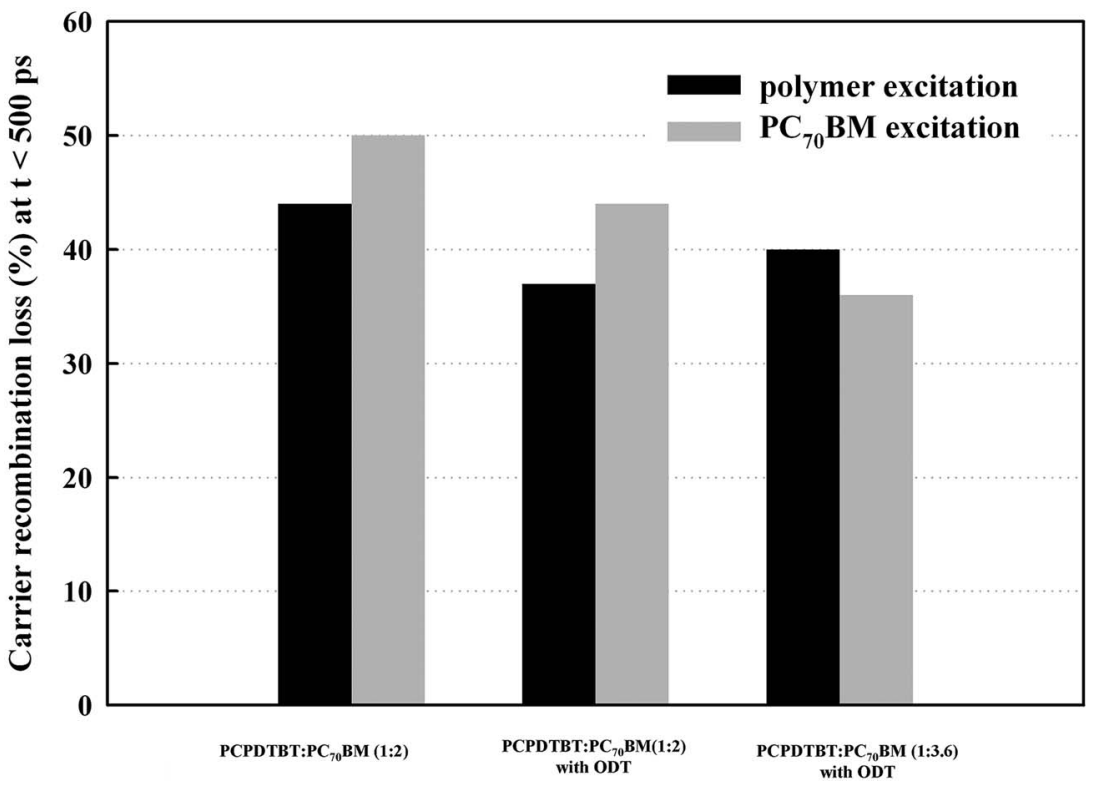

FIG. 5. Carrier recombination loss derived from $\mathrm{PB}$ decays of the PCPDTBT: $\mathrm{PC}_{70} \mathrm{BM}$ BHJ materials (1:2 composite fabricated with and without ODT and 1:3.6 composite fabricated with ODT) following the photoexcitation of the polymer and that of $\mathrm{PC}_{70} \mathrm{BM}$.

decays are fitted to a sum of two exponential terms-one with time constant of $47-87$ ps followed by the constant PB in the nanosecond regime.

The initial fast PB-decay time constant of $2-10 \mathrm{ps}$ is consistent with the carrier evolution times deduced from the PIA data (Fig. 3). Since the dissociation of CT bound state proceeds via transition of the hole into neighboring polymer networks (i.e., a limiting process for the ground state recovery of the polymer), the same time constants can be found for the PIA and PB decays. As demonstrated in the detailed analysis of the PIA decay, the $\sim 250$ ps and 47-87 ps components result from the recombination of the CT bound state with the neutral ground state following the photoexcition of PCPDTBT and that of $\mathrm{PC}_{70} \mathrm{BM}$, respectively. Therefore, the relative contribution of these components to the $\mathrm{PB}$ recovery provides a measurement of the carrier loss. An analysis of the PB data obtained using photoexcitation into the polymer absorption band $(700 \mathrm{~nm})$ indicates a $44 \%$ carrier loss for the 1:2 composite prepared without the ODT, and $37 \%$ and $40 \%$ for the 1:2 and 1:3.6 composites processed with ODT, respectively. The analysis of the $\mathrm{PB}$ data obtained using photoexcitation primarily into the $\mathrm{PC}_{70} \mathrm{BM}$ absorption band $(500$ $\mathrm{nm}$ ) indicates $50 \%$ carrier loss for the 1:2 composite prepared without the ODT and $44 \%$ and $36 \%$ for the $1: 2$ and 1:3.6 composites processed with ODT, respectively. These estimates of the initial loss of carriers are depicted in Fig. 5. Although the carrier losses are reduced in the films processed with ODT (similar to the reduced carrier losses in P3HT:PCBM BHJ materials after thermal annealing), the magnitude of the reduction is not sufficient to explain the observed factor of 2 increase in the power conversion efficiency.

\section{E. Carrier transport}

As demonstrated in the mobility data obtained from FETs, the improved electron transport seems to be the origin of the increased efficiency. Carrier mobility values were deduced from the transconductance characteristics of FETs
(Ref. 20) made from the PCPDTBT: $\mathrm{PC}_{70} \mathrm{BM}$ composites. The hole and electron mobilities were inferred from the $I_{\mathrm{ds}}$ $-V_{\text {gs }}$ curves [Fig. 6(a) is plotted in Fig. 6(b)]. The mobility $(\mu)$ was obtained in the saturation regime using $I_{\mathrm{ds}}$ $=\left(\mathrm{WC}_{i} / 2 L\right) \mu\left(V_{\mathrm{gs}}-V_{T}\right)^{2}$, where $W$ is the channel width (1 $\mathrm{mm})$ of the device, $L$ is the channel length $(5 \mu \mathrm{m}), V_{T}$ is the threshold voltage, $C_{i}$ is the capacitance of the $\mathrm{SiO}_{2}$ dielectric layer, $I_{\mathrm{ds}}$ is the drain source current, and $V_{\mathrm{gs}}$ is the gate source voltage. $^{20}$

Figure 6(b) shows the electron and hole mobilities obtained from various composites. Although the hole mobility is insensitive to whether or not the BHJ film was processed using the ODT, the electron mobility increases significantly in films processed with the ODT additive; the electron mobility increases by a factor of 4 in the 1:2 BHJ composite and a factor of 7.5 in the 1:3.6 BHJ composite. We note that ODT is a good solvent for the $\mathrm{PC}_{70} \mathrm{BM}$ but it does not dissolve PCPDTBT. As a result, the high boiling point ODT organizes the formation of the $\mathrm{PC}_{70} \mathrm{BM}$ networks during the spincasting process resulting in better connectivity and mobility of the $\mathrm{PC}_{70} \mathrm{BM}$ networks.

Recent steady-state and transient photoconductivity studies indicate the enhanced photoconductive response and longer carrier lifetime in the composite processed with ODT, which are consistent with the fast transient spectroscopy data reported here. Thus, the improved power conversion efficiency in BHJ films processed with ODT stems from the improved electron mobility, greater yield of mobile carrier, and longer carrier lifetime in composites processed with ODT.

We note that although the best power conversion efficiency $\left(\eta_{e}=5.6 \%\right)$ obtained from the PCPDTBT:PC ${ }_{70} \mathrm{BM}$ composites represents a significant improvement, the power conversion efficiency of this system is still limited to $38 \%$ carrier loss in early times, ${ }^{16}$ larger than that in semicrystalline rrP3HT:PCBM composites [where the corresponding loss is only $16 \%$ (Ref. 17)]. Thus, there is an opportunity for further enhancement of the power conversion efficiency. 

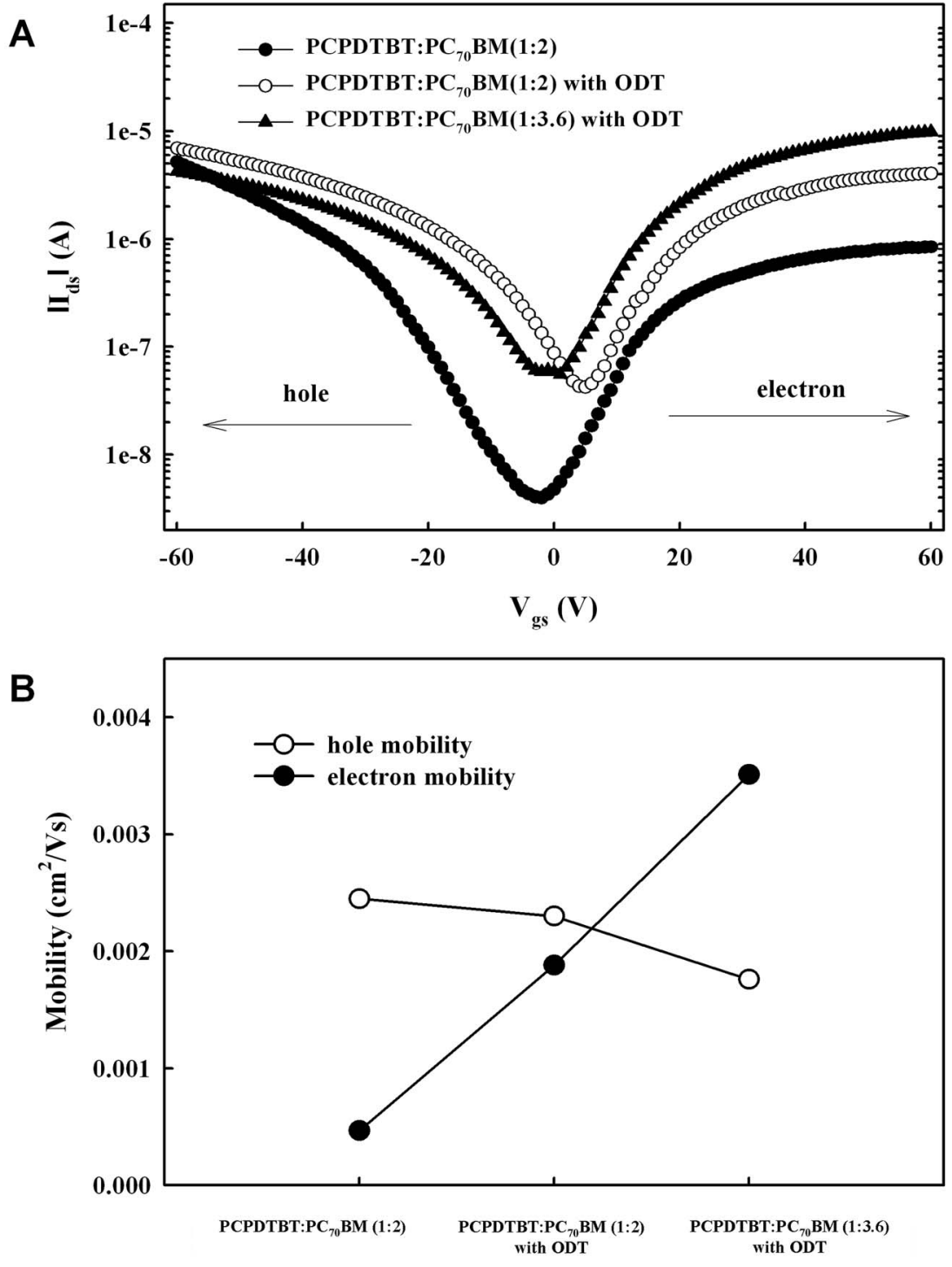

FIG. 6. (a) Bipolar transfer characteristics of bipolar FET devices made from PCPDTBT: $\mathrm{PC}_{70} \mathrm{BM}$ BHJ materials (1:2 composite fabricated with and without ODT and 1:3.6 composite fabricated with ODT). (b) Plots of the electron and hole mobilities inferred from (a).

Photogeneration of mobile charge carriers are also studied in BHJ films comprised of PCPDTBT and $\mathrm{PC}_{70} \mathrm{BM}$ using 1,8-octanedithiol (ODT) as a processing additive. The carrier mobilities were obtained from field effect transistor measurements. Recombination loss of mobile carriers at early times is reduced and the electron mobility within the $\mathrm{PC}_{70} \mathrm{BM}$ network is enhanced in PCPDTBT: $\mathrm{PC}_{70} \mathrm{BM}$ composites fabricated using 1,8-octanedithiol as processing additive during film formation. As a result, the ODT leads to an increase in photovoltaic conversion efficiency from $2.8 \%$ to $5.5 \%$.

\section{CONCLUSIONS}

Ultrafast spectroscopic studies have once again demonstrated the two-step process involved in the generation of mobile carriers following the photoexcitation of the polymer and the $\mathrm{PC}_{70} \mathrm{BM}$. The initial ultrafast $(<1 \mathrm{ps})$ electron or hole transfer to a CT bound state is followed (after 50-250 ps) by the generation of mobile carriers. The quantum efficiency for mobile carrier generation from the CT state is significantly influenced by BHJ morphology. Although the carrier losses are reduced in the films processed with ODT (similar to the reduced carrier losses in P3HT:PCBM BHJ materials after thermal annealing), the magnitude of the reduction is not sufficient to explain the observed factor of 2 increase in the power conversion efficiency. From the analysis of carrier transport in FETs, we find the increased electron mobility in the PCPDTBT: $\mathrm{PC}_{70} \mathrm{BM}$ composites when fabricated with ODT, which is indicative of the enhanced connectivity of $\mathrm{PC}_{70} \mathrm{BM}$ networks. The improved electron mobility appears to be the primary origin of the improved power conversion efficiency in BHJ films processed with ODT.

\section{SUPPORTING INFORMATION AVAILABLE}

Steady-state PIA spectra in the midinfrared regime of PCPDTBT: PC $_{70}$ BM BHJ materials (S1). ${ }^{21,22,25}$

\section{ACKNOWLEDGMENTS}

This research was supported by the Air Force Office of Scientific Research, the U.S. Department of Energy, and by the Konarka Technologies. I.W. Hwang received partial support from the Korea Research Foundation (Grant No. KRF2005-M01-2004-000-20037-0-C00179). The PCPDTBT ma- 
terial was supplied for our use by Konarka Technologies.

${ }^{1}$ W. Ma, C. Yang, X. Gong, K. Lee, and A. J. Heeger, Adv. Funct. Mater. 15, 1617 (2005).

${ }^{2}$ J. Y. Kim, S. H. Kim, H.-H. Lee, K. Lee, W. Ma, X. Gong, and A. J. Heeger, Adv. Mater. (Weinheim, Ger.) 18, 572 (2006).

${ }^{3}$ G. Li, V. Shrotriya, J. Huang, Y. Yao, T. Moriarty, K. Emery, and Y. Yang, Nat. Mater. 4, 864 (2005).

${ }^{4}$ M. Reyes-Reyes, K. Kim, and D. L. Carroll, Appl. Phys. Lett. 87, 083506 (2005).

${ }^{5}$ C. Winder and N. S. Sariciftci, J. Mater. Chem. 14, 1077 (2004).

${ }^{6}$ M. R. Andersson, O. Thomas, W. Mammo, M. Svensson, M. Theander, and O. Inganäs, J. Mater. Chem. 9, 1933 (1999).

${ }^{7}$ A. Dhanabalan, J. K. J. van Duren, P. A. van Hal, J. L. J. van Dongen, and R. A. J. Janssen, Adv. Funct. Mater. 11, 255 (2001).

${ }^{8}$ C. J. Brabec, C. Winder, N. S. Sariciftci, J. C. Hummelen, A. Dhanabalan, P. A. van Hal, and R. A. J. Janssen, Adv. Funct. Mater. 12, 709 (2002).

${ }^{9}$ C. Winder, G. Matt, J. C. Hummelen, R. A. J. Janssen, N. S. Sariciftci, and C. J. Brabec, Thin Solid Films 403-404, 373 (2002).

${ }^{10}$ M. Svensson, F. Zhang, S. Veenstra, W. J. H. Verhees, J. C. Hummelen, J. M. Kroon, O. Inganäs, and M. R. Andersson, Adv. Mater. (Weinheim, Ger.) 15, 988 (2003).

${ }^{11}$ X. Wang, E. Perzon, F. Oswald, F. Langa, S. Admassie, M. R. Andersson, and O. Inganäs, Adv. Funct. Mater. 15, 1665 (2005).

${ }^{12}$ H. Aarnio, M. Westerling, R. Österbacka, M. Svensson, M. R. Andersson, T. Pascher, J. Pan, V. Sundström, and H. Stubb, Synth. Met. 155, 299 (2005).

${ }^{13}$ Z. Zhu, D. Waller, R. Gaudiana, M. Morana, D. Mühlbacher, M. Scharber, and C. Brabec, Macromolecules 40, 1981 (2007).

${ }^{14}$ D. Mühlbacher, M. Scharber, M. Morana, Z. Zhu, D. Waller, R. Gaudiana, and C. Brabec, Adv. Mater. (Weinheim, Ger.) 18, 2884 (2006).

${ }^{15}$ I.-W. Hwang, C. Soci, D. Moses, Z. Zhu, D. Waller, R. Gaudiana, C. J. Brabec, and A. J. Heeger, Adv. Mater. (Weinheim, Ger.) 19, 2307 (2007).

${ }^{16}$ V. D. Mihailetchi, L. J. A. Koster, J. C. Hummelen, and P. W. M. Blom, Phys. Rev. Lett. 93, 216601 (2004).

${ }^{17}$ I.-W. Hwang, D. Moses, and A. J. Heeger, J. Phys. Chem. C 112, 4350 (2008).

${ }^{18}$ J. Peet, J. Y. Kim, N. E. Coates, W. L. Ma, D. Moses, A. J. Heeger, and G. C. Bazan, Nat. Mater. 6, 497 (2007).

${ }^{19}$ B. Kraabel, D. McBranch, N. S. Sariciftci, D. Moses, and A. J. Heeger, Phys. Rev. B 50, 18543 (1994).

${ }^{20}$ S. Cho, J. Yuen, J. Y. Kim, K. Lee, and A. J. Heeger, Appl. Phys. Lett. 89, 153505 (2006).

${ }^{21}$ R. Österbacka, C. P. An, X. M. Jiang, and Z. V. Vardeny, Science 287, 839 (2000).

${ }^{22}$ X. M. Jiang, R. Österbacka, O. Korovyanko, C. P. An, B. Horovitz, R. A. J. Janssen, and Z. V. Vardeny, Adv. Funct. Mater. 12, 587 (2002).

${ }^{23}$ D. Chirvase, J. Parisi, J. C. Hummelen, and V. Dyakonov, Nanotechnology 15, 1317 (2004)

${ }^{24}$ J. Peet, C. Soci, R. C. Coffin, T. Q. Nguyen, A. Mikhailovsky, D. Moses, and G. C. Bazan, Appl. Phys. Lett. 89, 252105 (2006).

${ }^{25}$ See EPAPS Document No. E-JAPIAU-104-112813 for steady-state photoinduced absorption spectrum in the mid-infrared regime of PCPDTBT:PC70BM BHJ materials. For more information on EPAPS, see http://www.aip.org/pubservs/epaps.html. 